\title{
The Role of Explosion Limit Chemical Kinetics in $\mathrm{H}_{2}-\mathrm{CO}-\mathrm{O}_{2}$ Detonations
}

\author{
P. L. Lu, ${ }^{*}$ E. K. Dabora, $\dagger$ and J. A. Nicholls \\ Department of Aerospace Engineering, University of Michigan, Ann Arbor, Michigan, U.S.A.
}

\begin{abstract}
The role of explosion limit kinetics is explored by applying three different explcsicn fimits to detonation waves traveling at a critical Mach number in stoichiometric mixture of $\mathrm{H}_{2}-\mathrm{CO}-\mathrm{O}_{2}$. Such waves are achieved by subjecting normal ChapmanJouguet waves to a gaseous boundary and bringing them to a critical velocity below which quenching would result. It is found that the critical velocities can be explained by the explosion limit idvanced by Minkoff and Tipper when recent applicable rate constants (slightly modified) are used. In addition, this explosinn limit seems to give a reasonable prediction of the lean detonation limit of $\mathrm{CO}-\mathrm{H}_{2}-\mathrm{O}_{2}$ mixtures, although it fails to agree with the experimental evidence at the rich detonation limit end found in the literature.
\end{abstract}

\section{Introduction}

It is well known that a steady detonation wave cannot be maintained in hydrogen-free $\mathrm{CO}-\mathrm{O}_{2}$ mixtures and that the reaction of such mixtures are extremely sensitive to trace amounts of hydrogen or hydrogen compounds. Dixon and Walls [1] and Campbell and Woodhead [2] were probably the first to discover the strong effect of a very small amount of hydrogen on the cietonability of $\mathrm{CO}_{-} \mathrm{O}_{2}$ mixtures. They found that the addition of about $1 \%$ (by volume) of hydrogen to the otherwise undetonable $\mathrm{CO}-\mathrm{O}_{2}$ mixture would make it detonable. Campbell and Woodhead also discovered the peculiar spinning propagation wave phenomena in such a mixture. Bone et al. [3] later noticed that the frequency of spin in such detonation waves is affected by the hydrogen concentration in the mixture. Since then, because of this

- Present address: Explosive Laboratory. Picatinny Arsenal, Dover, New Jersey, U.S.A.

† Present address: Department of Aerospace Engineering. University of Connecticut, Sterrs, Connecticut, U.S.A. hydrogen-sensitive spinning-frequency property, the detonation waves in $\mathrm{CO}-\mathrm{O}_{2}$ mixtures, with small amounts of hydrogen added, have been used by various investigators, such as Dove and Wagner [4] and Voitsekhovsky et al. [5], as a means for studying spinning detonation. Laffitte [6] investigated the effect of hydrogen concentration on the detonation limits of $\mathrm{H}_{2}-\mathrm{CO}-\mathrm{O}_{2}$ mixtures. He found that the first $2 \%$ of hydrogen, replacing the $\mathrm{CO}$ in a $\mathrm{CO}_{-} \mathrm{O}_{2}$ mixture, lowered the lean fuel-oxygen limit of detonation from 38 to $28.4 \%$, and that firther hydrogen replacement produced a decreasing effect. Kistiakowsky and Kyad [7] studied the overall effect of hydrogen on the reaction time of detonations in $\mathrm{H}_{2}-\mathrm{CO}-\mathrm{O}_{2}$ mixtures diluted with xenon and concluded that the inverse reaction time was proportional to the square root, of the ratio of the partial pressures of hydrogen and carbon m onoxide.

More recently, Myers et al. [8] investigatid the influence of $\mathrm{H}_{2}$ on the induction period preceding rapid $\mathrm{CO}_{2}$ formation in shock- 
heated $\mathrm{H}_{2}-\mathrm{CO}-\mathrm{O}_{2}$-Ar mixtures in the $0-0.43 \%$ range of $\mathrm{H}_{2}$ concentration. They reported that at a temperature below about $2400^{\circ} \mathrm{K}$ the induction period generally decreased with increasing initial $\mathrm{H}_{2}$ concentration. They further suggested 'that with hydrogen concentration larger than $0.43 \%$ by volum: the induction periods of $\mathrm{H}_{2}-\mathrm{CO}-\mathrm{O}_{2}$ systems and $\mathrm{H}_{2}-\mathrm{O}_{2}$ systems would be comparable and independent of $\mathrm{H}_{2}$ concenitration. Later Brokaw [9] suggested a vinemical scheme to explain the data of Myers et al. and estimated that their mixtures must have contained a mole fraction of $7 \times 10^{-6}$ to $3 \times 10^{-5}$ water vapor.

The study of $\mathrm{H}_{2}$ effects on $\mathrm{CO}-\mathrm{O}_{2}$ reaction in deflagrative combustion was started at the same time that such investigators as Dixon and Campbell studied the $\mathrm{H}_{2}$ effects on detonations in $\mathrm{CO}-\mathrm{O}_{2}$ mixtures. Buckler and Norrish [10] were the first to investigate systematically the effects of hydirugen concentration (up to $10 \%$ ) on the explosion limit in dry $\mathrm{CO}-\mathrm{O}_{2}$ mixtures. Their experiments were conducted at low temperatures (below $565^{\circ} \mathrm{C}$ ) and pressures (less than $125 \mathrm{~mm} \mathrm{Hg}$ ). They concluded that the catalytic effect of hydrogen in $\mathrm{CO}-\mathrm{O}_{2}$ reactions could be described by introducing two extra chain-termination reactions of $\mathrm{CO}$ in addition to the reaction mechanism of hydrogen and oxygen.

Lewis and Von Elbe [11] suggested a kinetic mechanism to explain the water vapor-catalyzed $\mathrm{CO}-\mathrm{O}_{2}$ reaction experiment performed by $\mathrm{Hac}-$ man et al. [12]. They also suggested that the effects of water vapor and hydrogen on the $\mathrm{CO}-\mathrm{O}_{2}$ reaction were the same. Thus, with a small modification of their $\mathrm{H}_{2} \mathrm{O}-\mathrm{CO}-\mathrm{O}_{2}$ explosion limit mechanism, they derived a mechanism to describe Buckler and Norrish's experiment. Their mechanism was different from that of Buckler and Norrish in that they included an ozone reaction which originated from their hydrogen-free $\mathrm{CO}-\mathrm{O}_{2}$ reaction mechanism. However, the role of ozone in the latte $r$ case has been questioned by Gordon and Knipe [13] and Dickens et al. [14] on the grounds that it is too slow a mechanism to be important.

The two reaction mechanisms proposed by Lewis and Von Elbe [11] and by Buckle: and Norrish [10], as well as a thire one due to Minkoff and Tipper $[1] j$, which is similar to the Buclele-Norrish mechanism except that it includes some additional elementary reactions, are examined in this paper for their applicability to the experimental explosion limit results of $\mathrm{H}_{2}-\mathrm{CO}-\mathrm{O}_{2}$ mixtures.

\section{Explosion Limit Criterion}

A stable detonation involves the coupling of a shock front and a rapid chemical reaction which releases heat to sustain the detonation. The unburned mixture must be rapidly heated and compressed by the shock front to such a state that a very rapid reaction takes place close to the shock front. Belles [16] suggested that, in hydrogen-oxygen mixtures and other chain-branching reacting mixtures, the shocked but unreacted gases in the detonation wave front must be in a state that satisfies the explosion limit requirement, which is predicted by the chemical reaction scheme of a given mixture composition. The shocked gas state depends on the shock wave strength (Mach number), initial pressure, temperature, and composition; hence the explosion condition may be expressed in terms of these variables. Therefore, for a given composition mixture and set of initial conditions, there is a critical shock strength above which a propagating detonation wave is expected. Detonation waves propagating at a Mach number less than the critical wave strength will quench.

Belles's criterion extends the second explosion limit condition to higher pressure and temperature conditions than were previously accepted [11]. However, recent studies by Brokaw [17], Voevodsky and Soloukhin [18], and Dabora et al. [19] support the validity of Belles's assumption for hydrogen and oxygen 
mixtures. Brokaw calculated the ignition delay in the neighborhood of the lean limit of detonability of oxygen and hydrogen. His calculation indicated also that the second explosion limit concition must be satisfied for a stable detonation in the hydrogen-oxygen system. Voevodsky and Soloukhin's experimental study of the shock ignition of hydrogen and oxygen also indicated that the second explosion limit predicted accurately the explosive ignition condition of the shocked mixture. Dabora

Table 1. Reaction Schencs for CO-H $-\mathrm{H}_{2}-\mathrm{O}_{\mathrm{n}}$ Mixtures as Proposed by Lewis and Von Elbe [11], Buckler and Norrish [10], and Minkoff and Tipper [15]

Other Number
Authors Used in
Number This Puper

Lewis and Von Elbe

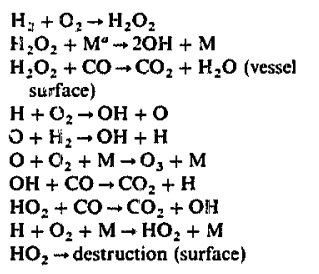

$\begin{array}{cc}\underset{\mathbf{x} X X}{ } & \ldots \\ \mathbf{X X X I} & \ldots \\ \text { II } & \text { II } \\ \text { III } & \text { III } \\ \mathbf{X X} & \mathbf{X X} \\ \mathbf{X X X I I} & \ldots \\ \mathbf{X X X I I I} & \ldots \\ \text { VI } & \text { v] } \\ \text { XII } & \ldots\end{array}$

Buckler and Norrish

$$
\begin{aligned}
& \mathrm{H}+\mathrm{O}_{2} \rightarrow \mathrm{OH}+\mathrm{O} \\
& \mathrm{O}+\mathrm{H}_{2} \rightarrow \mathrm{OH}+\mathrm{H} \\
& \mathrm{OH}+\mathrm{H}_{2} \rightarrow \mathrm{H}_{2} \mathrm{O}+\mathrm{H} \\
& \mathrm{OH}+\mathrm{CO} \rightarrow \mathrm{CO}_{2}+\mathrm{H} \\
& \mathrm{H}+\mathrm{O}_{2}+\mathrm{M} \rightarrow \mathrm{HO}_{2}+\mathrm{M} \\
& \mathrm{O}+\mathrm{CO}+\mathrm{M} \rightarrow \mathrm{CO}_{2}+\mathrm{M} \\
& \quad \text { Minkof and Tipper }
\end{aligned}
$$

$\mathrm{OH}+\mathrm{H}_{2} \rightarrow \mathrm{H}_{2} \mathrm{O}+\mathrm{H}$

$\mathrm{H}+\mathrm{O}_{2} \rightarrow \mathrm{OH}+\mathrm{O}$

$\mathrm{O}+\mathrm{H}_{2} \rightarrow \mathrm{OH}+\mathrm{H}$

$\mathrm{OH}+\mathrm{CO} \rightarrow \mathrm{CO}_{2}+\mathrm{H}$

$\mathrm{H}+\mathrm{O}_{2}+\mathrm{M} \rightarrow \mathrm{HO}_{2}+\mathrm{M}$

$\mathrm{H}+\mathrm{CO}+\mathrm{M} \rightarrow \mathrm{HCO}+\mathrm{M}$

$\mathrm{HCO}+\mathrm{O}_{2} \rightarrow \mathrm{CO}+\mathrm{HO}_{2}$ (very fast)

$\mathrm{CO}+\mathrm{HO}_{2} \rightarrow \mathrm{CO}_{2}+\mathrm{CH}$

$\mathrm{O}+\mathrm{CO}+\mathrm{M} \rightarrow \mathrm{CO}_{2}+\mathrm{M}$

$\mathrm{HO}_{2} \rightarrow$ destruction (wall)

- $\mathrm{M}=$ some third body. verified that the calculated critical Mach number at various compositions in hydrogen and oxygen agreed quite well with his experimental data.

The reaction schemes for $\mathrm{CO}-\mathrm{H}_{2}-\mathrm{O}_{2}$ suggested in Fiefs. 11, 10, and 15 result in different explosion limits. These reaction schemes are shown in Table 1 for convenience.

The derived explosion limits are, respectively, as follows:

$$
\begin{aligned}
& \frac{2 k_{2}}{k_{6}[\mathrm{M}]}=1+\frac{k_{20}\left[\mathrm{O}_{2}\right][\mathrm{M}]}{k_{3}\left[\mathrm{H}_{2}\right]} \\
& \frac{2 k_{2}}{k_{6}[\mathrm{M}]}=1+\frac{k_{7}[\mathrm{CO}][\mathrm{M}]}{k_{3}\left[\mathrm{H}_{2}\right]}
\end{aligned}
$$

and

$$
\begin{gathered}
\frac{2 k_{2} k_{3}\left[\mathrm{H}_{2}\right]\left[\mathrm{O}_{2}\right]}{k_{7}[\mathrm{CO}][\mathrm{M}]+k_{3}\left[\mathrm{H}_{2}\right]}= \\
\left(1-\frac{k_{12}[\mathrm{CO}]}{k_{12}[\mathrm{CO}]+k_{13}}\right)\left(k_{6}\left[\mathrm{O}_{2}\right][\mathrm{M}]+\right. \\
\left.k_{9}[\mathrm{CO}][\mathrm{M}]\right)
\end{gathered}
$$

where the quantities in brackets are the species concentrations, and the $k$ 's are the reaction rate constants. Equation 3 is derived on the basis that the wall plays an important role in the destruction of $\mathrm{HO}_{2}$. However, in the time scale involved in the detonation experiments, $\mathrm{HO}_{2}$ can be considered unreactive. By considering the $\mathrm{HCO}$ radical to be either unreactive or rapidly reacting with $\mathrm{O}_{2}$ (reaction IXa), the steady-state approximation can be found to yield the following explosion limit:*

$$
\frac{2 k_{2}}{k_{6}[\mathrm{M}]}=\left(1+\frac{k_{7}[\mathrm{CO}][\mathrm{M}]}{k_{3}\left[\mathrm{H}_{2}\right]}\right)\left(1+\frac{k_{9}[\mathrm{CO}]}{k_{6}\left[\mathrm{O}_{2}\right]}\right)
$$

It is clear that the explosion limits expressed in Eqs. 2 and 4 reduce to the well-accepted explosion limit

$$
2 k_{2} / k_{6}[\mathrm{M}]=1
$$

* The outhors are grateful to the reviewer for suggesting this argument to them. 
Table 2. Reaction Rate Constants (Rcf. 20)

\begin{tabular}{lcl}
\hline \multicolumn{1}{c}{ Reaction } & Reaction No. & \multicolumn{1}{c}{ Rate Constant } \\
\hline $\mathrm{H}+\mathrm{O}_{2} \rightarrow \mathrm{OH}+\mathrm{O}$ & II & $k_{2}=0.332 \times 10^{-9} \exp (-16.700 / R T) \mathrm{cm}^{3} / \mathrm{sec}$ \\
$\mathrm{O}+\mathrm{H}_{2} \rightarrow \mathrm{OH}+\mathrm{H}$ & II & $k_{3}=0.996 \times 10^{-10} \mathrm{exp}(-10,000 / R T) \mathrm{cm}^{3} / \mathrm{sec}$ \\
$\mathrm{H}+\mathrm{O}_{2}+\mathrm{M} \rightarrow \mathrm{HO}_{2}+\mathrm{M}$ & VI & $k_{6}=0.441 \times 10^{-29}(1 / T) \mathrm{cm}^{6} / \mathrm{sec}$ \\
$\mathrm{O}+\mathrm{CO}+\mathrm{M} \rightarrow \mathrm{CO}_{2}+\mathrm{M}$ & VII & $k_{7}=0.8265 \times 10^{-33} \mathrm{~cm}^{6} / \mathrm{sec}^{6}$ \\
$\mathrm{H}+\mathrm{O}+\mathrm{M} \rightarrow \mathrm{HCO}+\mathrm{M}$ & IX & $k_{\phi}=0.790 \times 10^{-33} \mathrm{~T}^{0.11} \mathrm{~cm}^{6} / \mathrm{sec}$ \\
$\mathrm{O}+\mathrm{C}_{2}+\mathrm{M} \rightarrow \mathrm{O}_{3}+\mathrm{M}$ & $\mathrm{XX}$ & $k_{20}=0.73 \times 10^{-33} \exp (600 / R T) \mathrm{cm} / \mathrm{sec}$ \\
\hline
\end{tabular}

" $R$ is expressed in cal/mole " $K ; T$, in ${ }^{2} K$.

"Reaction rates $k_{6 *} k_{7} k_{4}$ and $k_{20}$ are bascd on $\mathrm{H}_{2}$ as the third body with an afficiency of unity.

of the iydrogen-oxygen system when the CO concentration is negligible. This is true also of the explosion limit in Eq. 1 if reaction $\mathrm{XX}$ is to be neglected, as is presumably legitimate in the absence of $\mathrm{CO}$ [11].

In order to translate the explosion limit equations into functions of Mach number, the rate constants of the relevant reactions must be known. The rate constants used in this investigation were taken from Browne et al. [20] and are shown in Table 2. If these values are substituted into the explosion limits, and the third-body concentrations, [M], are expressed in terms of temperature and pressure by means of the perfect-gas law, the explosion limits of Eqs.1.2, and 4 will be transformed, respectively, into

$$
\begin{aligned}
& A=B(1+C) \\
& A=B(1+D) \\
& A=B(1+D)(1+E)
\end{aligned}
$$

where

$$
\begin{aligned}
& A=2.054 \times 10^{-3} / f_{M} \\
& B=\left(P / T^{2}\right) \exp (16,700 / R T) \\
& C=0.0538(P / T)\left(f_{\mathrm{O}_{2}} / f_{M} / f_{\mathrm{H}_{2}}\right) \exp (10,600 / R T) \\
& E=0.0603(P / T)\left(f_{\mathrm{Co}} f_{M} / f_{\mathrm{H}_{2}}\right) \exp (10,000 / R T) \\
& E=0.1794 \times 10^{-4} T^{! .11}\left(f_{\mathrm{Co}} / f_{\mathrm{O}_{2}}\right)
\end{aligned}
$$

It should be noted that the hydrogen-oxygen explosion limit, Eq. 5, becomes

$$
A=B
$$

In the above expressions, $P$ is the pressure in atmospheres and $f$ is the mole fraction. In particular, $f_{\mathrm{M}}$ is the effective mole fraction of third bodies. For lack of better data, it is assumed that the efficiency of a given species is the same in all trimolecular reactions. Thus from (Ref. 11)

$$
f_{\mathrm{H} M}=f_{\mathrm{H}_{2}}+0.35 f_{\mathrm{o}_{2}}+0.77 f_{\mathrm{CO}}
$$

The temperature and pressure are those of the shocked but unreacting gas behind the shock front. Here, on the basis of the work of Toennies and Green [21] and Patch [22], one can assume that the unreacted gas after the shock is in the frozen state. Thus, for a given mixture at an initial temperature of $294^{\circ} \mathrm{K}$ and at a pressure of $1 \mathrm{~atm}$ (conditions used in this investigation), it is possible, by trial and error, to use the standard shock wave equations to find a "critical" Mach number, $M_{c}$, satisfying any of the explosion limit expressions.

\section{Experimental Method}

The experimental method used in this investigation is the same as that of Dabora et al. [19] and is described in detail by Lu [23]. Ir brief, the technique is to let a well-established steady 
detonation wave, traveling in a rectangular tube, be exposed on one side to an inert gas. The detonative mixture and the inert gas are separated by a thin film of negligible mechanical influence. A detonation thus processed usually slows down to a new steady velocity. The velocity decrement can be controlled by using suitable boundary gases and varying the detonation tube width. However, when the detonation velocity decreases beyond a critical limit, the detonation wave quenches into a shock of continuously decreasing velocity. It is this critical velocity (and hence critical Mach number, $M_{c}$ ) that is observed experimentally and compared with that obtained from Eqs. 6-8.

In this investigation, the tube depth was $0.36 \mathrm{in}$. and the width was varied from 0.2 to 0.5 in. Several inert gases, such as nitrogen, argon, Freon 14, Freon 116 and Freon C-318, were used as the boundary gas to achieve the desired relief effect. In general, heavier gases were used when the $\mathrm{CO}$ concentration in the detonative mixture was large. The overall composition of the detonative mixture was stoichiometric, and the only variations therefore made were in the relative amounts of $\mathrm{CO}$ and $\mathrm{H}_{2}$ used.

\section{Experimental Results}

The experimental critical Mach numbers wert determined for stoichiometric fuel-oxygen mixtures. Four mixtures were used, namely, those with $\mathrm{CO}$ volumetric ratios in the fuel of 0,15 , 50 , and $75 \%$. At the critical limit five runs were made for each mixture. In addition, runs with decreasing amounts of hydrogen were made, without subjecting the detisnation wave to a gaseous boundary, in order to determine lie stoichiometric mixture with the minimum amount of hydrogen in which steady detonation waves can bc made. This was determined to be a mixture with $1.5 \% \mathrm{H}_{2}$ in the fuel.

The experimental results are shown in Fig. 1, in which the average and the range for each

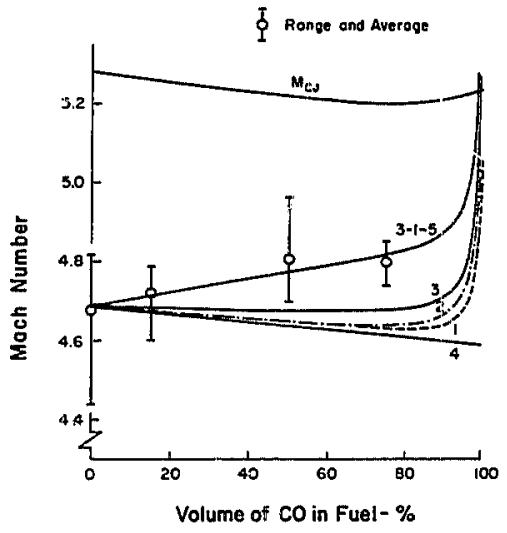

Figure 1. Theoretical C-J and critical Mach numbers of stoichiometric $\mathrm{CO}-\mathrm{H}_{2}-\mathrm{O}_{2}$ mixtures.

mixture are included. The same figure shows a curve corresponding to the Chapman-Jouguet (C-J) Mach number of detonation, computed using the computer program of Zeleznik and Gordon [24]. The other curves, labeled 1-4, correspond, respectively, to the explosion limits of Lewis and Von Elbe (Eqs. 1 and 6), Buckler and Norrish (Eqs. 2 and 7), Minkoff and Tipper (Eqs. 4 and 8 ), and the $\mathrm{H}_{2}-\mathrm{O}_{2}$ explosion limit (where $\mathrm{CO}$ is considered to participate as a third body) (Eqs. 5 and 14). The difference between th: C-J curve and each of the other curves marks the extent by which the Mach number can be reduced before quenching takes place.

In expressions 1, 2, ind 4 the terms on the right-hand side are due to reactions considered important when $\mathrm{CO}$ is included in $\mathrm{H}_{2}-\mathrm{O}_{2}$ mixtures. The effects of these terms on the critical Mach number can be seen by comparing curves 1,2 , and 3 with curve 4 . It is clear that the $\mathrm{CO}$ reaction terms turn the $M_{c}$ curves upward and that the larger the effect, the earlier the upward turn starts. 
In Fig. 1, curve 4 can imnediately be dismissed, for it indicates that a fure $\mathrm{CO}-\mathrm{O}_{7}$ mixture can detorate, a couclusion strary to our and other experimental finding;. The othe: curves, although pla $a_{4}$ to, do no seem to fit the quenching deturuation results very weli.

In view of the possible. uncertainties in the rate constants, it was decided to vary these constants with the aim of bringing the resultant curves closer to the experimental results. First of all, no variation in the vaiue of the ratio $A / B$ was made, since a good agreemer.t with the $0 \%$ $\mathrm{CO}$ mixture result is obtained by all of the explosion limit criteria. However, the values of $C$ (Eq. 11), D (Eq. 12), and $E$ (Eq. 13) were varied as shown in Table 3.

The best agreement with our data was found for curve 3-1-5, shown in Fig. 1. In general, the other variations, although raising curves 1 , 2 , and 3 , never resulted in curves approaching the agreement of curve 3-1-5. Furthermore, in some cases the resultant curves started intersecting the C-J curve at $\mathrm{CO}$ compositions below
$98.5 \%$ in the fuel, thus contradicting out experimental finding that detonation is possible in such a mixture.

It should be pointed out that the value of $k_{9} / k_{6}$ from Table 2 is $1.59 \times 10^{-5} T^{1.11}$, which, when multiplied by 5 (corresponding to multiplying $E$ by 5) and evaluated at $800^{\circ} \mathrm{K}$, results in a ratio of 0.134 . This is close to the ratio of 0.17 found by Baldwin [25] in this temperature region, thus lending some justification to our choice of the factor 5 .

\section{Composition Limits}

The above explosion limit criteria and their variations were tested for their applicability to the prediction of detonation compostion limits. One example will serve to indicate how this wias done. Figure 2 shows the C-J detonation Mach number of $80 \% \mathrm{CO} /\left(\mathrm{CO}+\mathrm{H}_{2}\right)$ in various proportions with oxygen. On the same figure a plot of the critical Mach number corresponding to case $l$ is shown. Thus the intersection

Table 3. Variation of Applicable Rate Constants and Resultant Composithin Limits

\begin{tabular}{|c|c|c|c|c|c|c|}
\hline \multirow[t]{2}{*}{$\begin{array}{l}\text { Case or } \\
\text { Curve No. }\end{array}$} & \multirow{2}{*}{$\frac{\begin{array}{c}\text { Variation in } \\
\text { Rute Constant }\end{array}}{\mathrm{H}_{2} \% \text { in fuel : }}$} & \multicolumn{2}{|c|}{$\begin{array}{l}\text { L.ean Limit, } \\
\text { fuel vol. } \%\end{array}$} & \multicolumn{2}{|c|}{$\begin{array}{l}\text { Rich Limit. } \\
\text { fuel vol. } \%\end{array}$} & \multirow[t]{2}{*}{ R:marks } \\
\hline & & 1 & 10 & 1 & 10 & \\
\hline 1 & $C \times: 1$ & 35.5 & 22.3 & 89.0 & 89.9 & Figs. 1,3 \\
\hline 2 & $D \times I$ & 27.0 & 20.0 & 56.0 & 89.5 & Fig. 1 \\
\hline 3 & $E \times \mathrm{i}$ & 27.4 & 19.8 & 82.3 & 88.2 & Fig. 1 \\
\hline 4 & $(A=B)$ & 18.5 & Same & 90.0 & Same & Fig. 1 \\
\hline $1-5$ & $C \times 5$ & 66.5 & 30.0 & 37.0 & 89.5 & $\ldots$ \\
\hline $1-10$ & $c \times 10$ & $\ldots$ & 35.5 & $\ldots$ & 89.0 & $\cdots$ \\
\hline $2-10$ & $D \times 10$ & $\cdots$ & 26.8 & $\cdots$ & 86.5 & $\cdots$ \\
\hline $3-10-1$ & $D \times 10, E \times 1$ & $\ldots$ & 27.0 & $\ldots$ & 82.8 & $\ldots$ \\
\hline $3-1-5$ & $D \times 1, E \times 5$ & 29.5 & 20.3 & 67.0 & 83.0 & Figs. 1,3 \\
\hline $3-10-5$ & $D \times 10, E \times 5$ & $\ldots$ & 28.0 & $\ldots$ & 69.5 & $\ldots$ \\
\hline $3-1-2$ & $D \times 1, E \times 2$ & 27.5 & 20.0 & 78.5 & 87.0 & $\cdots$ \\
\hline $3-0.5-5$ & $D \times 0.5 . E \times S$ & 24.2 & 20.0 & 76.0 & 83.0 & $\ldots$ \\
\hline $3-0.2-5$ & $D \times 0.2, E \times 5$ & 21.3 & 19.3 & 80.5 & 83.3 & $\ldots$ \\
\hline $3-0.1-5$ & $D \times 0.1, E \times 5$ & 20.3 & 19.0 & 81.7 & 83.5 & $\ldots$ \\
\hline
\end{tabular}




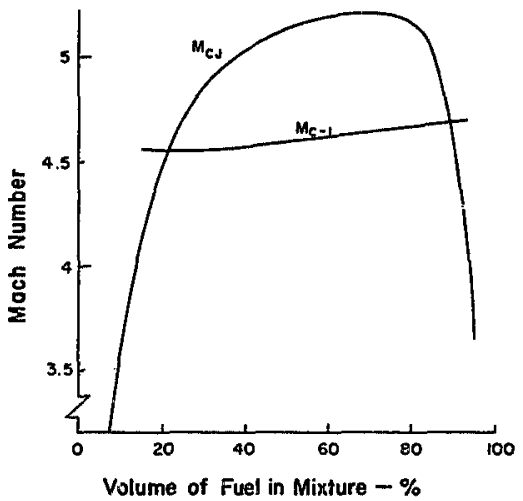

Figure 2. Theoretical C-J and critical Mach numbers of CO.- $\mathrm{H}_{2}-\mathrm{O}_{2}$ unixtures in which the $\mathrm{CO}$ content in the furel is $80 \%$.

point of these curves on the left-hand side indicates the lean limit, and that on the righthand side the rich limit. In general, the shapes of the $\mathrm{C}-\mathrm{J}$ curves for various $\mathrm{CO}$ compositions in the fuel were close to each other [23], reflecting the fact that the heating values of $\mathrm{CO}$ and $\mathrm{H}_{2}$ are not too different from each other. The shape and the level of the $M_{c}$ curves depended on the particular explosion limit criterion and the variation thereof. From many similar plots the results of both the lean and the rich limits were obtained; these are shown in Table 3. It can be seen that in general the addition of $\mathrm{H}_{2}$ to $\mathrm{CO}-\mathrm{O}_{2}$ mixtures widens the limits considerably. Such an effect, based on chemical kinetics grounds, was first pointed out by Belles and Ehlers [26], using the Lewis and Von Elbe explosion limit.

In order to complete the picture, we present in Fig. 3 the lean and rich limits corresponding to cases 1 and 3-1-5 and compare them with available experimental evidence on lean limits by Laffitte [6] and on rich limits as given in Ref. 11. The dramatic effect of substituting $\mathrm{CO}$ by $\mathrm{H}_{2}$ can clearly te seen in both cases. Case 1 (Lewis and Von Elbe) appears to give good results for both the lean and the rich limits, whereas case 3-1-5 shows good agreement on the lean-limit side but not as good on the richlimit side.

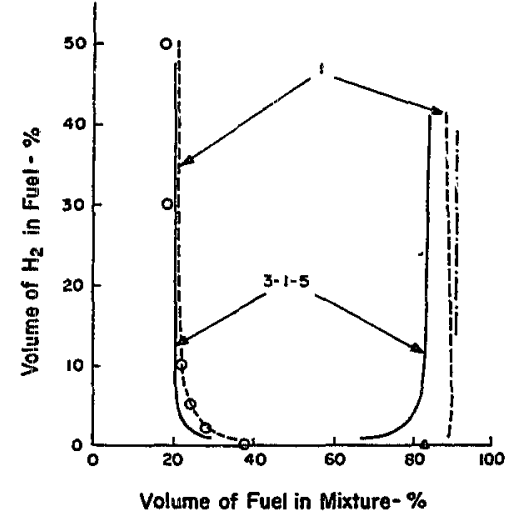

Figure 3. The effect of hydrogen on the lean and rich limits of $\mathrm{CO} \mathrm{O}_{2}$ mixtures.

\section{Conclusions}

On the basis of our experimental data of critical detonation Mach numbers together with the lean detonation limit, we conclude that the Minkoff and Tipper scheme resulting in the explosion limit expressed in Eq. 4 appears the best one examined when the rate variation $3-1-5$ is used. However, the rich limit does not seem to be well predicted by this scheme.

This work was supported in part by the Army Research Office under Contract DA-31-124$A R O-D-299$ to the University of Michigan. Calculations of the critical Mach numbers were 
performed at the University of Connecticut Computer Center, which is supported by National Science Foundation Grant GJ-9.

\section{References}

1. Dixon, H. B.. and Walis, N. S., J. Chem. Soc., 123, 1025 (1923).

2. Campegl, C.. and Woodhead. D. W.. J. Chem. Soc., 3010 (1926).

3. Bone. W. A., Fraser, R. P.. and Wheeler. W. H., Phil. Trans., 235A, 29 (1935-36).

4. Dove. J. E., and WAGNER. H. 3., Eighth Symposium (Internationul) on Combustion, p. 589. Williams \& Wilkins: Baltimore (1962).

5. VOITSEKHOVSKY, B. V.. Mitrofanov, V. V., and TropChIYAN. M. YE.. The Siructure of a Detonation Front in Gases (1963) (trans!. Foreign Technology Div., Wright-Patterson AFB, Ohio. AD 6\$3-821, February 1966).

6. LAfFitTe. P. F., Sci. Petrol., 4. 2995 (1938).

7. Kistiakowsky, G. B.. and Kydo, P. H., J. Chem. Phys., 25. 824 (1956).

8. Myers, B. F., SulzmanN, K. G. P., and Bartze. E. R.. J. Chem. Phy. 43, 1220 (1965).

9. BRokaw, R, S.. Eleventh Symposium (Imernational) on Conbustion, p. 1963. The Combustion Institute: Pittsburgh (1967).

10. Buckler. E. J., and Norkish, R. G. W.. Proc. Royal Soc. (London), Ser. A, 167, 318 (1938).

11. Lews, B.. and Von Elise, G.. Combustion, Flames and Explosions of Gases. Chap. III. Academic: New York (1961).

12. Hadman, G. Tizompson. H. W., and Hinshelwood, C. N.. Proc. Roval Soc, (London). Ser. A, 137. 87 (1932).

13. Gondon. A. S., and KNIPE, R. H., J. Phy's. Chem., 59. $1160(1955)$.
14. Dickens, P. G.. Dove. J. E., and Linnetr, J. W.. Trans. Faraday Soc.. 60, 539 (1964).

15. MINkoff, G. J., and Tipper, C. F. H.. Chemistry of Combustion Reactions, Chap. 2. Butterworths: London (1962).

16. Belles, F. E., Seventh Symposium (Internarional) on Combustion, p. 745. Butterworths: London (1959).

17. Brokaw, R. S.. Tenth Symposium (International) on Combustion, p. 269. The Combustion Institute: Pittsburgh (1965).

18. Volvodsky, V. V., and SoloukHIN, R. 1., Temh Symposium (Intornational) on Combustion, p. 297. The Combustion Institute: Pittsburgh (1965).

19. Dabora, E. K.. Nicholis, J. A., and Morrison, R. B., Tenth Symposium (International) on Combastion. p. 817. The Combustion Institute: Pittskurgh (1965).

20. Browne, W. G.. White. D. R., and SMOOKLER, G. R.. Twelfih Sympositm (International) on Combustion, p. 5,57. The Combustion Institute: Pittsburgh (1969).

21. Toennies. J. P.. and Greene. E. F.. J. Chem. Phys.. 26. 655 (1957).

22. PATCH, R. W, ARS J., 31, 46 (1961).

23. LU. P. L.. "The Structure and Kinetics of the $\mathrm{H}_{2}-\mathrm{CO}-\mathrm{O}$. Detonations." Ph. D. Thesis. The University of Michigan. Ann Arbor. Mich. (1968).

24. ZELE7.NIK. F. J.. and Gordon. S., "A General IBM 704 and 7090 Computer Program for Computation of Chemical Equilibrium Compositions, Rocket Performance. and Chapman-Jouguet Detonations." NASA Tech. Not TN D-14S4 (October 1962); see also NASA Tech. Note TN D-1637 (October 1963) and ARS J., 32. 607 (1962).

25. EialdWIN, R. R., JaCkSON, D., WALKer, R. W., and WeAster. S. J., Tenth Sympostum (International) on Combustion, p. 423. The Combustion Institute: Pittsburgh (1965).

26. Belles. F. E.. and Ehlers. J. G., ARS J., 32, 215 (1962).

(Received September, 1970; revised January. 1971) 